\title{
Identificación de los factores de reprobación en los estudiantes del primer nivel de la carrera de Medicina de la Escuela Superior Politécnica de Chimborazo
}

\section{Identification of the failing factors in the students of the First Level of the Medical Career of the Polytechnic School of Chimborazo}

Silvana Paola Ocaña Coello. ${ }^{1}$, Ángel Floresmilo Parreño Urquizo. ${ }^{2}$, Ángel Rigoberto Silva Delgado. ${ }^{3} \&$ Hanníbal Lorenzo Brito Moina. ${ }^{4}$

Recibido: 14-07-2019 / Revisado: 23-07-2019 /Aceptado: 15-08-2019/ Publicado: 10-09-2019

\begin{abstract}
DOI: https://doi.org/10.33262/cienciadigital.v3i3.4.877
The student failure rate was determined in the first semester of the medical career of the School of Public Health of the Higher Polytechnic School of Chimborazo in a period of eight academic semesters from October 2014 to August 2018, for which interviews were conducted teachers, administrative staff and authorities of the academic unit under study, obtaining primary information of students by subject that attend the first level, these data were tabulated and analyzed statistically determining that there is a low percentage of students failing, this result indicates that the ESPOCH, in accordance with article 5, letter b) of the LOES, has complied with the rights of students to have a quality higher education, and in this way assuming their social commitment, to provide competitive, qualified professionals, becoming a Higher education institution leader at national level.
\end{abstract}

Keywords: Reprobation, Students, Medicine, Public Health, ESPOCH

\begin{abstract}
Resumen
Se determinó la tasa de reprobación estudiantil en el primer semestre de la carrera de medicina de la Facultad de Salud Pública de la Escuela Superior Politécnica de Chimborazo en un lapso de ocho semestres académicos de octubre 2014 a agosto 2018, para lo cual, se realizó entrevistas a profesores, personal administrativo y autoridades de la unidad académica en estudio, obteniendo información primaria de estudiantes por materia que cursan el primer nivel, estos datos fueron tabulados y analizados estadísticamente determinando que existe un porcentaje bajo de reprobación de estudiantes, este resultado indica que la ESPOCH, de conformidad con el articulo 5 literal b) de la LOES, viene cumpliendo con los derechos de los estudiantes de tener una educación superior de calidad, y de esta manera asumiendo su compromiso social, de aportar profesionales competitivos, calificados, convirtiéndose en una institución de educación superior líder a nivel nacional.
\end{abstract}

1 Escuela Superior Politécnica de Chimborazo, Facultad de Salud Pública. Riobamba, Ecuador, socana@espoch.edu.ec

2 Escuela Superior Politécnica de Chimborazo, Facultad de Ciencias. Riobamba, Ecuador. aparreno@espoch.edu.ec

3 Escuela Superior Politécnica de Chimborazo, Facultad de Ciencias. Riobamba, Ecuador. angel.silva@espoch.edu.ec

4 Escuela Superior Politécnica de Chimborazo, Facultad de Ciencias. Riobamba, Ecuador. hbrito@espoch.edu.ec 
Palabras clave: Reprobación, Estudiantes, Medicina, Salud Pública, ESPOCH.

\section{Introducción}

La educación es uno de los pilares fundamentales en el desarrollo de un país, es decir, una sociedad educada ayuda a dinamizar su economía (Llanes \& et al, 2013), llevando de la mano la disminución de la pobreza de su población (QUINTERO, 2016), por tal motivo, el gobierno del Ecuador a través de la constitución de la Republica en su artículo 356 aprobada en referéndum por el pueblo ecuatoriano en el año 2008, determina que la educación superior pública será gratuita hasta el tercer nivel, consecuentemente el Estado invierte en educación pública para llegar a los estratos sociales más pobres, donde los jóvenes de escasos recursos puedan acceder a una Institución de Educación Superior. Por otro lado, con el fin de mejorar la calidad de educación superior en el Ecuador, en el año 2010 se promulga la Ley Orgánica de Educación Superior (LOES) en la que se establece organismos públicos que rigen el sistema de Educación Superior, siendo el Consejo de Educación Superior (CES) y el Consejo de Aseguramiento de la Calidad de la Educación Superior (CACES), mismos que abarcan funciones más integrales, puesto que no solamente tiene como objetivo garantizar el derecho a la educación superior, sino que se preocupa porque el nivel de calidad de esta sean elevados (Redacción Médica, 2016), de tal manera, que el rendimiento académico (Vélez, 2005) de los estudiantes especialmente del primer nivel sea alto, es decir, que no exista la reprobación y menos exista deserción por parte de ellos (Alvear, Maldonado, \& Cazar, 2014), es decir, lo que el gobierno y las universidades pretende es que sus estudiantes que ingresan puedan terminar su carrera. Pero en Ecuador aproximadamente un $25 \%$ de estudiantes que cursan el primer nivel en las carreras de medicina pierden el primer semestre (Castro \& Rivas , 2006), este fracaso no sólo impacta negativamente a los alumnos o su familia, sino también a todo el sistema de educación superior, dado que la tasa de retención de estudiantes (El Comercio, 2016) es uno de los indicadores más importantes y utilizados para la evaluación de la eficiencia de las universidades y/o politécnicas conforme al artículo 96 del Aseguramiento de la Calidad, por otro lado, la reprobación del $30 \%$ de las materias o créditos de su malla curricular cursada, conduciría a la pérdida definitiva de la gratuidad de la educación superior, problema que se constituye en una de las principales manifestaciones de fracaso de las instituciones de educación superior (Universidad de Costa Rica, 2007), que por lo general, se relaciona con factores de origen individual, económico, social, cultural, docente, institucional (HEREDIA \& et al, 2015), así como, el bajo nivel académico (desigualdad e inequidad) (Velásquez \& Mejía, 2009) de los jóvenes que provienen especialmente de colegios de la región costa y oriente. Por este motivo se consideró determinar el porcentaje de estudiantes que reprueban el primer semestre en la carrera de medicina en la ESPOCH en el período octubre 2014 - agosto 2018, para lo cual, se procedió a efectuar entrevistas a los estamentos de la facultad de salud pública, obteniendo información primaria de las estadísticas de estudiantes por materia que cursan el primer nivel, los datos fueron tabulados y analizados mediante la estadística inferencial determinando que existe apenas un 10,18 \% de reprobación de estudiantes del primer nivel, lo que indica, que el porcentaje de reprobación es bajo, lo que indica, que el rendimiento académico en la carrera de medicina de la ESPOCH en el período de análisis es exitoso al término del primer nivel.

\section{Metodología}

Se realizó un estudio exploratorio, transversal, retrospectivo, comparativo de la tasa de estudiantes del primer nivel de la carrera de Medicina de la ESPOCH reprobados en ocho períodos correspondiente a octubre 2014 - agosto 2018. La población de estudio se la analizó con la totalidad de alumnos en ocho períodos académicos legalmente matriculados, con un universo de 690 estudiantes del primer nivel de la carrera de Medicina de la Facultad de 
Salud Pública de la ESPOCH, con un promedio de 86 educandos por semestre académico, estos datos fueron obtenidos del sistema OASIS en la secretaría de la carrera de Medicina. Para determinar el porcentaje de estudiantes que repiten el primer nivel de la carrera se procedió a tabular los datos obtenidos del sistema OASIS y analizados en el programa average linkage, por semestre y período con sus respectivas materias, luego se procedió a determinar el porcentaje de estudiantes que han reprobado por materia y semestre en el período analizado. El resultado de este análisis determinó que el 10,18 \% de estudiantes en este período de análisis han reprobado al menos una materia.

\section{Resultados y discusión}

Tabla 1. Estudiantes matriculados, aprobados y reprobados en la carrera de Medicina, período octubre 2014 - febrero 2015

\begin{tabular}{|c|c|c|c|c|c|c|c|}
\hline No. & Materia & Código & Período & Matriculados & Aprobados & Reprobados & Retirados \\
\hline \multirow{8}{*}{1} & \multirow{8}{*}{ Sociedad y salud } & \multirow{8}{*}{ MFO3011 } & 1 & 82 & 79 & 3 & 0 \\
\hline & & & 2 & 101 & 96 & 3 & 2 \\
\hline & & & 3 & 107 & 106 & 1 & 0 \\
\hline & & & 4 & 131 & 128 & 3 & 0 \\
\hline & & & 5 & 135 & 134 & 1 & 0 \\
\hline & & & 6 & 120 & 119 & 1 & 0 \\
\hline & & & 7 & 2 & 2 & 0 & 0 \\
\hline & & & 8 & 2 & 2 & 0 & 0 \\
\hline \multirow{8}{*}{2} & \multirow{8}{*}{$\begin{array}{l}\text { Técnicas de } \\
\text { aprendizaje y } \\
\text { comunicación }\end{array}$} & \multirow{8}{*}{ MFO3021 } & 1 & 80 & 77 & 2 & 1 \\
\hline & & & 2 & 101 & 96 & 4 & 1 \\
\hline & & & 3 & 109 & 108 & 1 & 0 \\
\hline & & & 4 & 131 & 128 & 2 & 1 \\
\hline & & & 5 & 135 & 134 & 1 & 0 \\
\hline & & & 6 & 120 & 119 & 1 & 0 \\
\hline & & & 7 & 2 & 2 & 0 & 0 \\
\hline & & & 8 & 3 & 3 & 0 & 0 \\
\hline \multirow{8}{*}{3} & \multirow{8}{*}{$\begin{array}{l}\text { Biología } \\
\text { Humana }\end{array}$} & \multirow{8}{*}{ MFO3031 } & 1 & 80 & 78 & 1 & 1 \\
\hline & & & 2 & 100 & 83 & 3 & 14 \\
\hline & & & 3 & 119 & 117 & 1 & 1 \\
\hline & & & 4 & 132 & 128 & 4 & 0 \\
\hline & & & 5 & 135 & 128 & 1 & 6 \\
\hline & & & 6 & 125 & 124 & 1 & 0 \\
\hline & & & 7 & 2 & 2 & 0 & 0 \\
\hline & & & 8 & 2 & 2 & 0 & 0 \\
\hline \multirow{8}{*}{4} & \multirow{8}{*}{$\begin{array}{l}\text { Química } \\
\text { Orgánica }\end{array}$} & \multirow{8}{*}{ MFO3041 } & 1 & 92 & 89 & 1 & 2 \\
\hline & & & 2 & 100 & 94 & 3 & 3 \\
\hline & & & 3 & 108 & 107 & 0 & 1 \\
\hline & & & 4 & 132 & 124 & 4 & 4 \\
\hline & & & 5 & 139 & 117 & 1 & 21 \\
\hline & & & 6 & 142 & 136 & 1 & 5 \\
\hline & & & 7 & 6 & 6 & 0 & 0 \\
\hline & & & 8 & 2 & 2 & 0 & 0 \\
\hline
\end{tabular}

Fuente: Secretaría Carrera de Medicina ESPOCH, 2019 
Tabla 2. Estudiantes matriculados, aprobados y reprobados en la carrera de Medicina, período octubre 2014 - febrero 2015 (continuación)

\begin{tabular}{|c|c|c|c|c|c|c|c|}
\hline No. & Materia & Código & Período & Matriculados & Aprobados & Reprobados & Retirados \\
\hline \multirow{8}{*}{5} & \multirow{8}{*}{$\begin{array}{c}\text { Lógica } \\
\text { Matemática }\end{array}$} & \multirow{8}{*}{ MFO3051 } & 1 & 82 & 79 & 3 & 0 \\
\hline & & & 2 & 101 & 95 & 4 & 2 \\
\hline & & & 3 & 109 & 108 & 1 & 0 \\
\hline & & & 4 & 131 & 127 & 3 & 1 \\
\hline & & & 5 & 136 & 135 & 1 & 0 \\
\hline & & & 6 & 122 & 121 & 1 & 0 \\
\hline & & & 7 & 2 & 2 & 0 & 0 \\
\hline & & & 8 & 2 & 2 & 0 & 0 \\
\hline \multirow{8}{*}{6} & \multirow{8}{*}{$\begin{array}{l}\text { Historia de la } \\
\text { Medicina }\end{array}$} & \multirow{8}{*}{ MFO3061 } & 1 & 81 & 79 & 2 & 0 \\
\hline & & & 2 & 100 & 95 & 3 & 2 \\
\hline & & & 3 & 107 & 107 & 0 & 0 \\
\hline & & & 4 & 131 & 128 & 3 & 0 \\
\hline & & & 5 & 135 & 134 & 0 & 1 \\
\hline & & & 6 & 122 & 121 & 1 & 0 \\
\hline & & & 7 & 2 & 2 & 0 & 0 \\
\hline & & & 8 & 2 & 2 & 0 & 0 \\
\hline
\end{tabular}

Fuente: Secretaría Carrera de Medicina ESPOCH, 2019

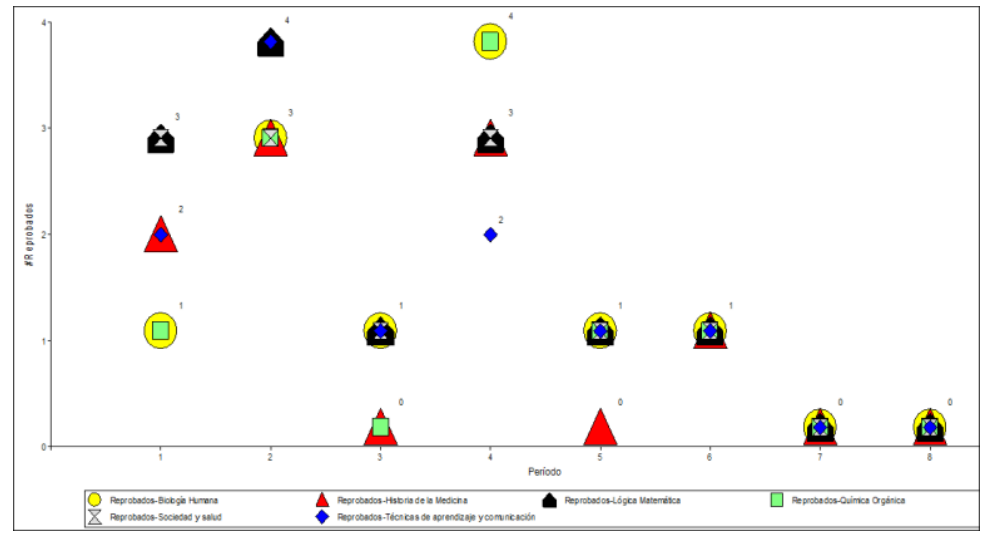

Figura 1: Reprobados en función del período por materia Fuente: Baquero Jenner, 2019.

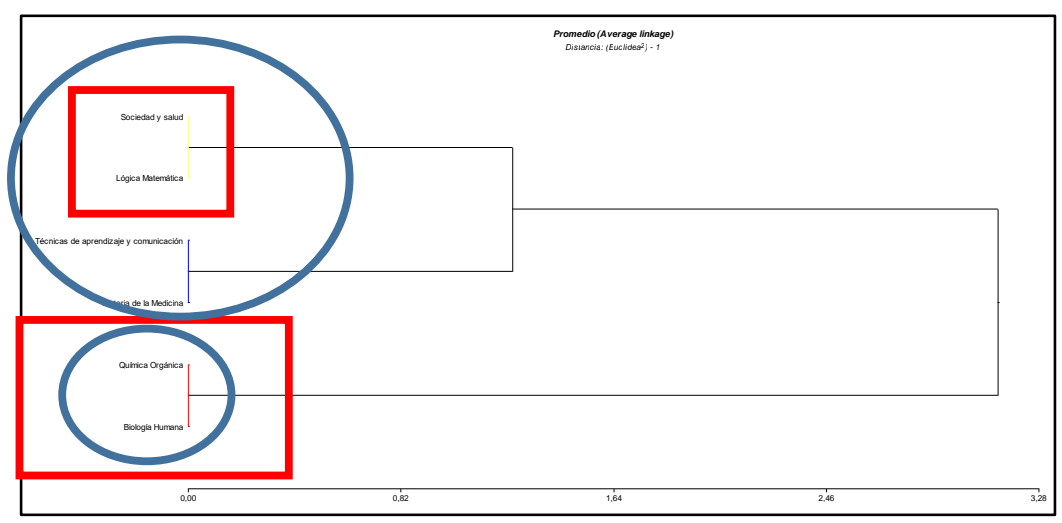

Figura 2: Análisis de conglomerados para el período octubre 2014-febrero 2015 (average linkage) y distancia euclídea cuadrada

Fuente: Baquero Jenner, 2019. 


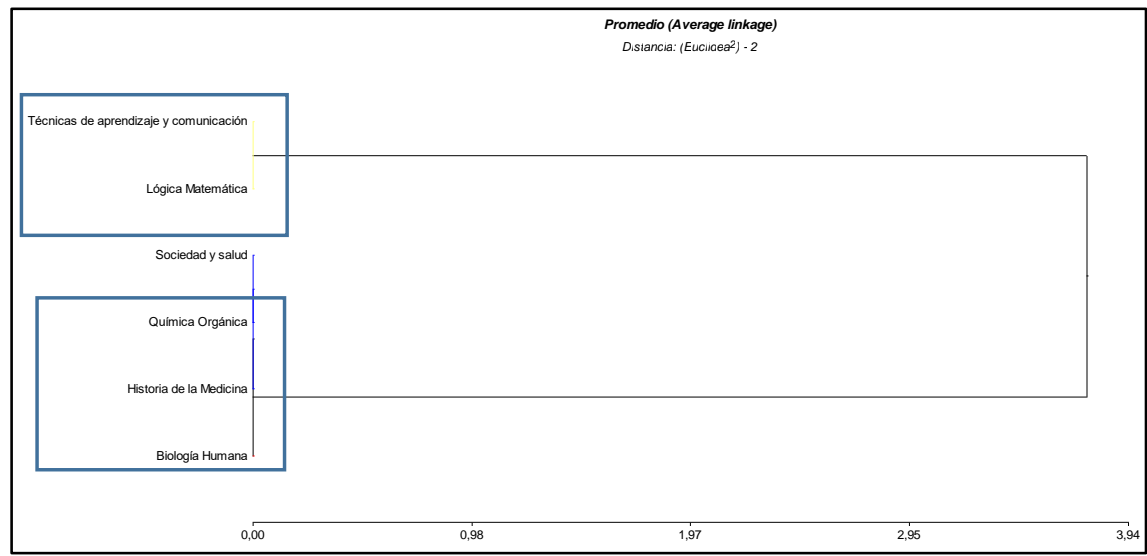

Figura 3. Análisis de conglomerados para el período abril 2015-agosto 2015 (average linkage) y distancia euclídea cuadrada.

Fuente: Baquero Jenner, 2019

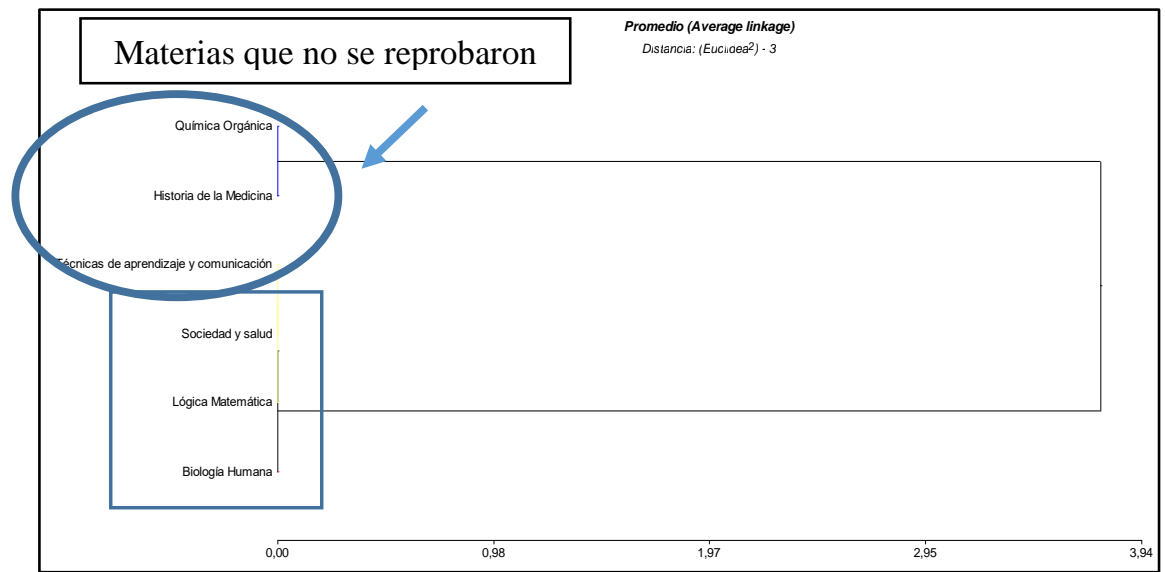

Figura 4: Análisis de conglomerados para el período octubre 2015-marzo 2016 (average linkage) y distancia euclídea cuadrada.

Fuente: Baquero Jenner, 2019

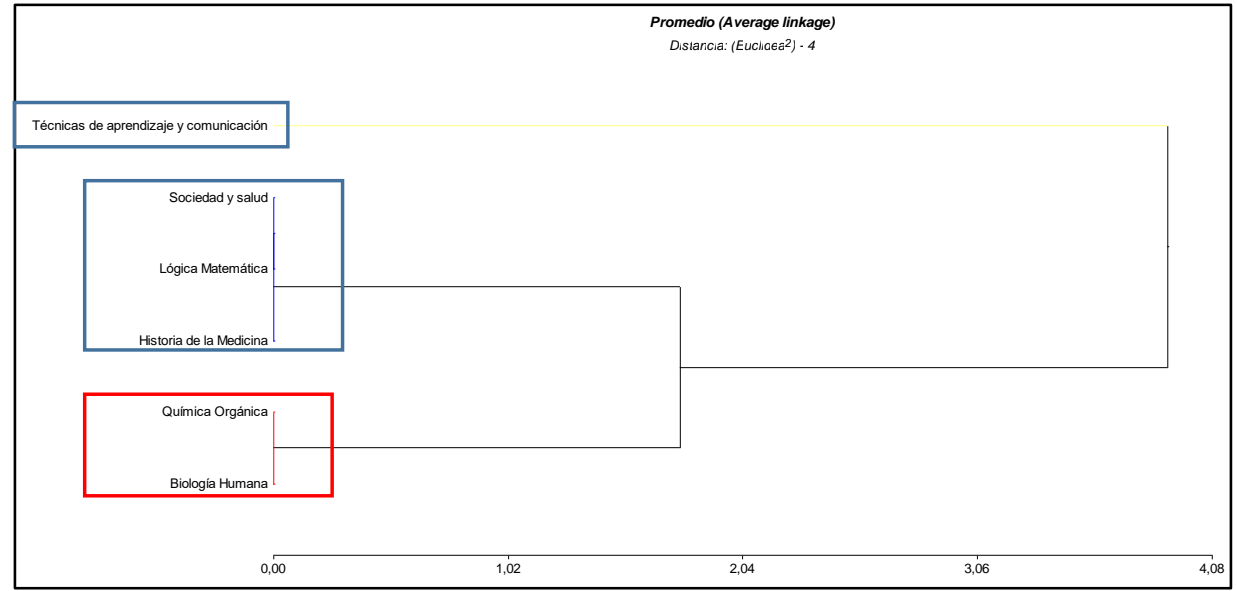

Figura 5: Análisis de conglomerados para el período abril 2016-agosto 2016 (average linkage) y distancia euclídea cuadrada.

Fuente: Baquero Jenner, 2019 


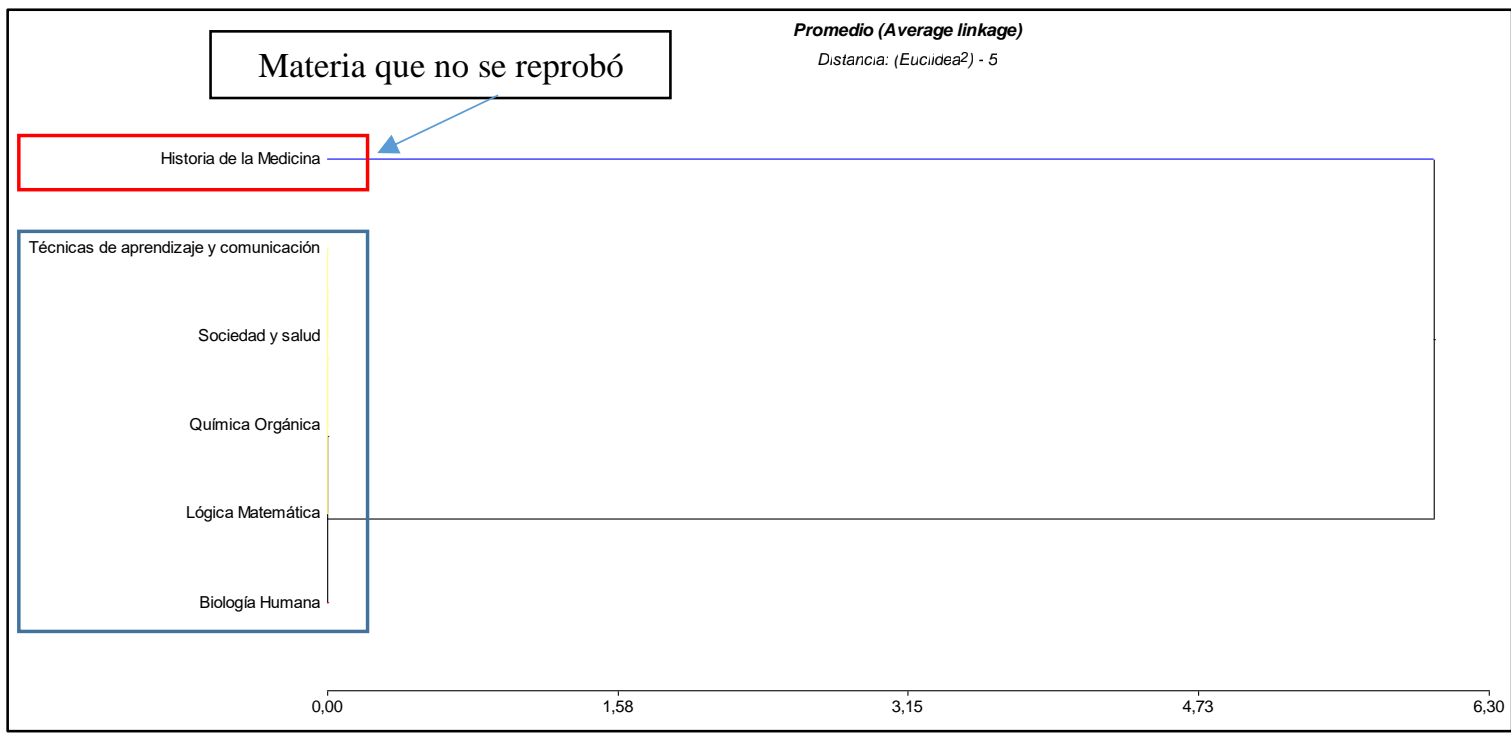

Figura 6: Análisis de conglomerados para el período octubre 2016-marzo 2017 (average linkage) y distancia euclídea cuadrada.

Fuente: Baquero Jenner, 2019

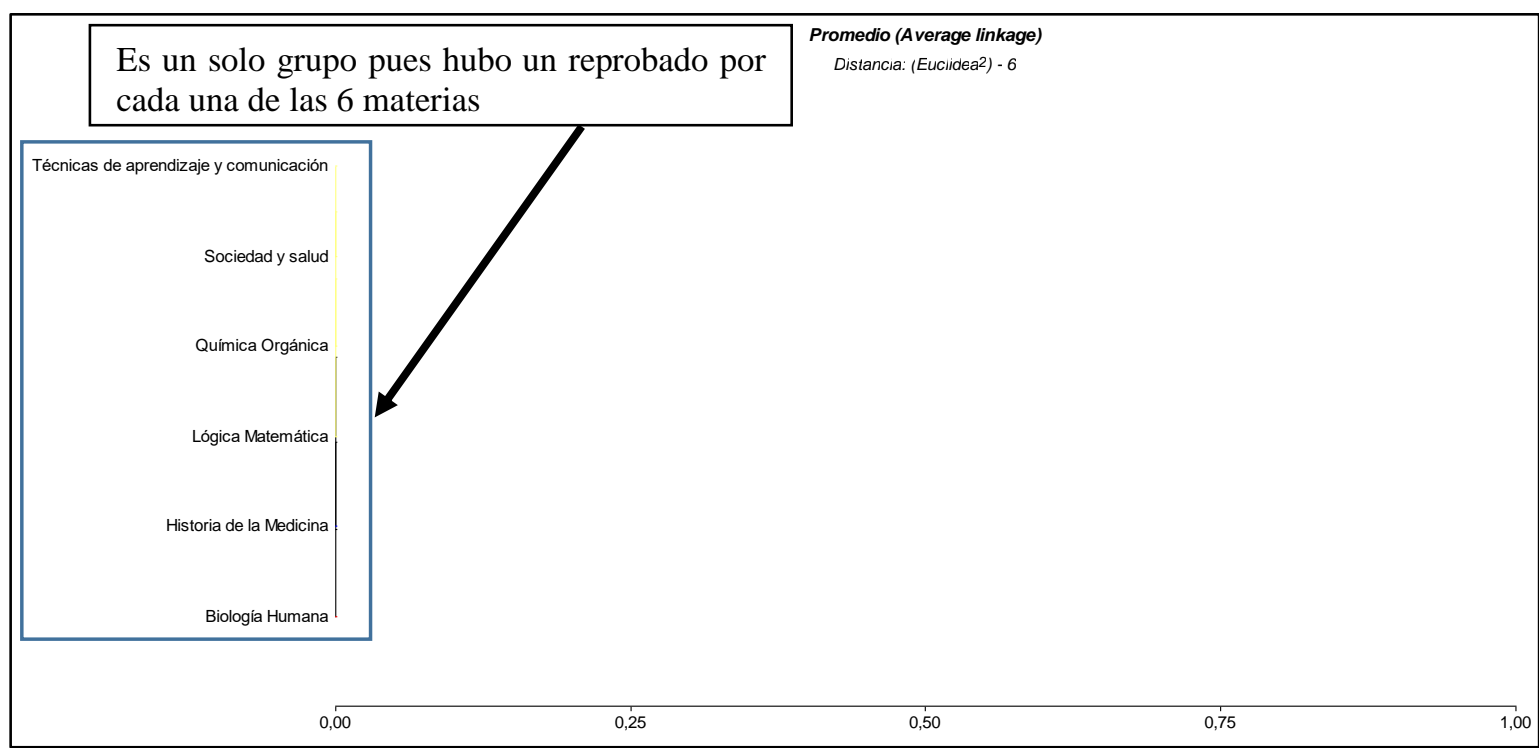

Figura 7. Análisis de conglomerados para el período abril 2017-agosto 2017 (average linkage) y distancia euclídea cuadrada.

Fuente: Baquero Jenner, 2019

De aquí que los dos siguientes períodos no se reportaron reprobados, por lo tanto, no se realizó el análisis de conglomerados. 
Tabla 2. Análisis de reprobados en función del período por materia

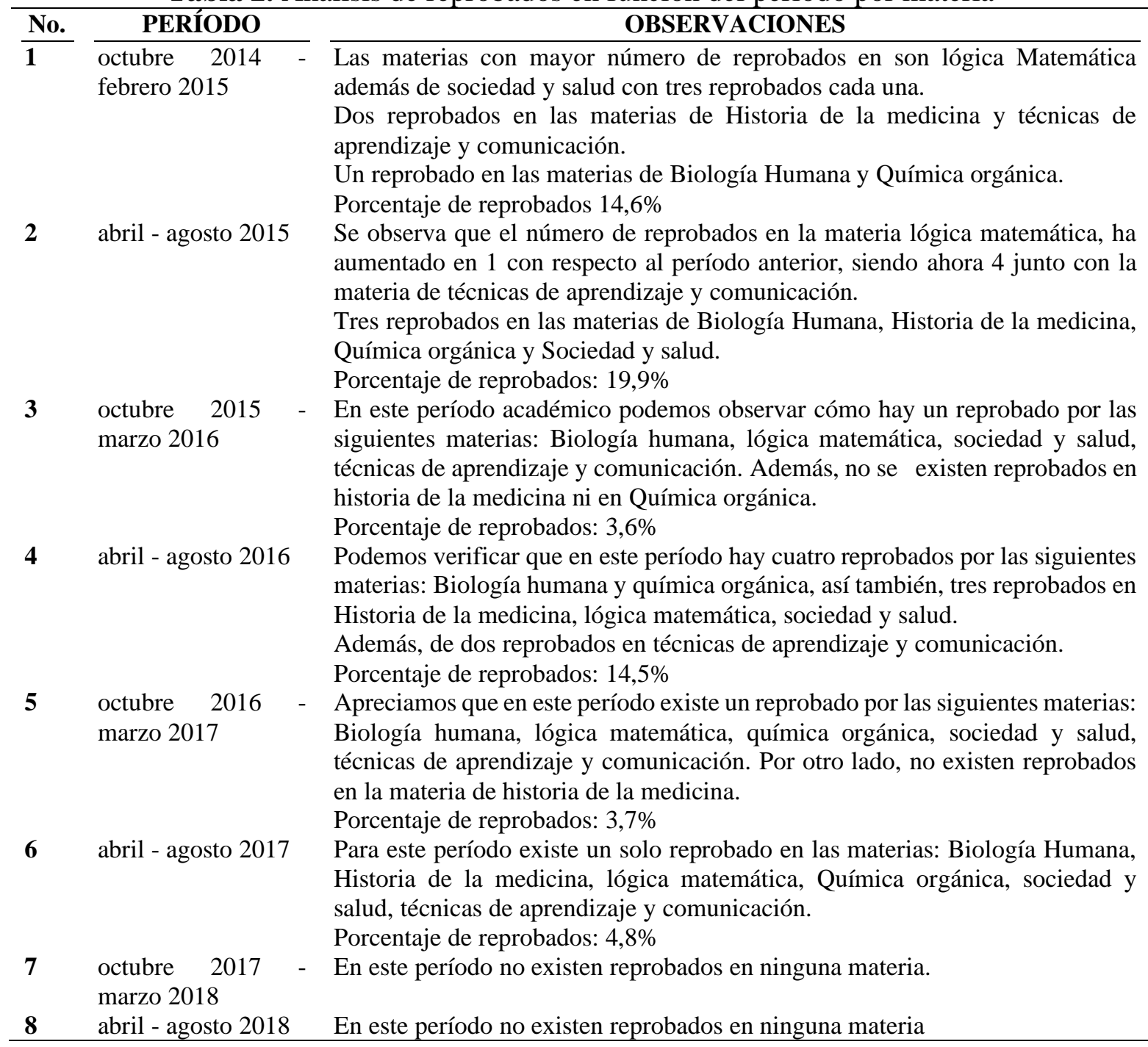

Fuente: Baquero Jenner, 2019

Tabla 3. Reprobados en función del período por materia y período académico

\begin{tabular}{clcc}
\hline No. & \multicolumn{1}{c}{ PERÍODO } & APROBADOS (\%) & REPROBADOS (\%) \\
\hline 1 & octubre 2014 - febrero 2015 & 85,40 & 14,60 \\
2 & abril - agosto 2015 & 80,10 & 19,90 \\
3 & octubre 2015 - marzo 2016 & 96,40 & 3,60 \\
4 & abril - agosto 2016 & 85,50 & 14,50 \\
5 & octubre 2016 - marzo 2017 & 96,30 & 3,70 \\
6 & abril - agosto 2017 & 95,20 & 4,80 \\
7 & octubre 2017 - marzo 2018 & 100,00 & 0,00 \\
8 & abril - agosto 2018 & 100,00 & 0,00 \\
PROMEDIO & $\mathbf{8 9 , 8 2}$ & $\mathbf{1 0 , 1 8}$ \\
\hline
\end{tabular}

Fuente: BRITO Hanníbal, BAQUERO Jenner, 2019.

Luego del análisis estadístico efectuado al período octubre 2014 - agosto 2018, se determinó que el 89,82 \% de estudiantes del primer semestre de la carrera de medicina de la facultad de salud pública de la ESPOCH aprueba en una o varias asignaturas, es decir, es un porcentaje alto, esto debido a que, los docentes se encuentran preparados y capacitados conforme al artículo 156 de la LOES, en concordancia con el artículo 349 
de la Constitución de la Republica, circunstancia que le permite impartir sus respectivas cátedras con elevado nivel académico y científico, cumpliendo de esta manera con la misión institucional de formar profesionales e investigadores competentes, para contribuir al desarrollo sustentable del país.

\section{Conclusiones}

$\checkmark$ La ESPOCH al ser líder en educación superior garantiza la formación integral de sus estudiantes.

$\checkmark$ En el período octubre 2014 - febrero 2015, el 14,60\% de estudiantes del primer nivel de la carrera de medicina de la ESPOCH repite una o varias materias.

$\checkmark$ En el período abril - agosto 2015, el 19,90\% de estudiantes del primer nivel de la carrera de medicina de la ESPOCH repite una o varias materias.

$\checkmark$ En el período octubre 2015 - marzo 2016, el 3,60\% de estudiantes del primer nivel de la carrera de medicina de la ESPOCH repite una o varias materias.

$\checkmark$ En el período abril - agosto 2016, el 14,50\% de estudiantes del primer nivel de la carrera de medicina de la ESPOCH repite una o varias materias.

$\checkmark$ En el período octubre 2016 - marzo 2017, el 3,70\% de estudiantes del primer nivel de la carrera de medicina de la ESPOCH repite una o varias materias.

$\checkmark$ En el período abril - agosto 2017, el 4,80 \% de estudiantes del primer nivel de la carrera de medicina de la ESPOCH repite una o varias materias.

$\checkmark$ En los períodos octubre 2017 - marzo 2018 y abril - agosto 2018, no existe estudiantes que han repetido una o varias materias.

$\checkmark$ En la carrera de medicina de la ESPOCH existe un 10,18 \% de reprobación de estudiantes en el primer nivel.

$\checkmark$ Existe una tasa alta de aprobación del primer nivel de la carrera de medicina.

\section{Referencias bibliográficas}

Alvear , C., Maldonado, F., \& Cazar, M. (2014). Asociación entre indicadores de rendimiento académico y la aprobación del primer año en la Facultad de Medicina. Cuenca.

Castro, R., \& Rivas , G. (2006). Sociedad Hoy. Estudio sobre el fenómeno de la deserción y retención escolar en localidades de alto riesgo. Concepción, Chile.

Consejo de Educación Superior. (12 de 10 de 2010). Ley Orgánica de Educación Superior. Obtenido de https://www.educacionsuperior.gob.ec/.../LEY_ORGANICA_DE_EDUCACION_ SUP..

Educación Médica Superior. (2017). Reprobación en estudiantes de Medicina de la Universidad Nacional Autónoma de México. 31.

El Comercio. (2016). 98\% de estudiantes de medicina reprobados en universidad argentina. Quito.

El Universo. (4 de mayo de 2010). Casi la mitad de estudiantes pierde el pre de medicina.

Heredia, M., \& et al. (2015). Deserción estudiantil en las carreras de ciencias de la salud en el Perú. Comunicación.

Llanes, A., \& et al. (2013). Revista de la Escuela de Medicina Tampico Dr. Alberto Romo Caballero. Factores asociados a la reprobación de los estudiantes de la licenciatura de Médico Cirujano.

Quintero, I. (2016). Análisis de las causas de deserción universitaria. Bogotá: UNAD. 
Redacción Médica. (2016). La mitad de estudiantes de Medicina no terminan la carrera . Quito: se.

Universidad de Costa Rica. (2007). Revista Educación. Factores asociados al rendimiento académico en estudiantes universitarios, una reflexión desde la calidad de la educación superior pública.

Velásquez, C., \& Mejía , J. (2009). Rendimiento académico y abuso - dependencia de sustancias psicoactivas en los estudiantes de la universidad de Antioquia, 2009. Antioquia, Colombia.

Vélez, R. (2005). Factores asociados al rendimiento académico en estudiantes de medicina. Cuenca.

F., \& Cazar, M. (2014). Asociación entre indicadores de rendimiento académico y la aprobación del primer año en la Facultad de Medicina. Cuenca.

Castro, R., \& Rivas , G. (2006). Sociedad Hoy. Estudio sobre el fenómeno de la deserción y retención escolar en localidades de alto riesgo. Concepción, Chile.

Consejo de Educación Superior. (12 de 10 de 2010). Ley Orgánica de Educación Superior. Obtenido https://www.educacionsuperior.gob.ec/.../LEY_ORGANICA_DE_EDUCACION_ SUP..

Educación Médica Superior. (2017). Reprobación en estudiantes de Medicina de la Universidad Nacional Autónoma de México. 31.

El Comercio. (2016). 98\% de estudiantes de medicina reprobados en universidad argentina. Quito.

El Universo. (4 de mayo de 2010). Casi la mitad de estudiantes pierde el pre de medicina.

Heredia, M., \& et al. (2015). Deserción estudiantil en las carreras de ciencias de la salud en el Perú. Comunicación.

Llanes, A., \& et al. (2013). Revista de la Escuela de Medicina Tampico Dr. Alberto Romo Caballero. Factores asociados a la reprobación de los estudiantes de la licenciatura de Médico Cirujano.

Quintero, I. (2016). Análisis de las causas de deserción universitaria. Bogotá: UNAD.

Redacción Médica. (2016). La mitad de estudiantes de Medicina no terminan la carrera. Quito: se.

Universidad de Costa Rica. (2007). Revista Educación. Factores asociados al rendimiento académico en estudiantes universitarios, una reflexión desde la calidad de la educación superior pública.

Velásquez, C., \& Mejía, J. (2009). Rendimiento académico y abuso - dependencia de sustancias psicoactivas en los estudiantes de la universidad de Antioquia, 2009. Antioquia, Colombia.

Vélez, R. (2005). Factores asociados al rendimiento académico en estudiantes de medicina. Cuenca.

\section{¿Ciencia}




\section{PARA CITAR EL ARTÍCULO INDEXADO.}

Ocaña Coello, S., Parreño Urquizo, Ángel, Silva Delgado, Ángel, \& Brito Moina, H. (2019). Identificación de los factores de reprobación en los estudiantes del primer nivel de la carrera de Medicina de la Escuela Superior Politécnica de Chimborazo. Ciencia Digital, 3(3.4.), 317-326. https://doi.org/10.33262/cienciadigital.v3i3.4.877

\section{LCiencia}

El artículo que se publica es de exclusiva responsabilidad de los autores y no necesariamente reflejan el pensamiento de la Revista Ciencia Digital.

El artículo queda en propiedad de la revista y, por tanto, su publicación parcial y/o total en otro medio tiene que ser autorizado por el director de la Revista Ciencia Digital.
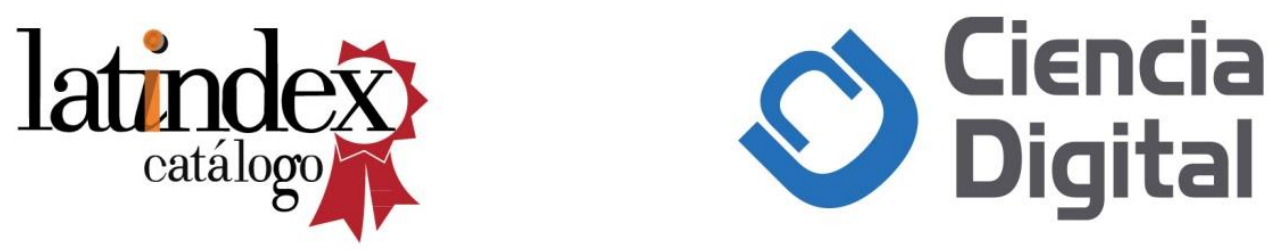